\title{
Increased number of pulmonary megakaryocytes in COVID-19 patients with diffuse alveolar damage: an autopsy study with clinical correlation and review of the literature
}

\author{
Mariel F. Valdivia-Mazeyra ${ }^{1}$ - Clara Salas ${ }^{2}$. Jesús M. Nieves-Alonso ${ }^{3} \cdot$ Luz Martín-Fragueiro $^{2} \cdot$ Carmen Bárcena $^{4}$. \\ Patricia Muñoz-Hernández ${ }^{1}$ - Karen Villar-Zarra ${ }^{5}$ • Javier Martín-López ${ }^{2}$ - Fernando Ramasco-Rueda ${ }^{3}$ • Javier Fraga ${ }^{1}$. \\ José A. Jiménez-Heffernan ${ }^{1}$ (10)
}

Received: 2 July 2020 / Revised: 17 August 2020 / Accepted: 2 September 2020 / Published online: 11 September 2020

(C) Springer-Verlag GmbH Germany, part of Springer Nature 2020

\begin{abstract}
Pulmonary megakaryocytes participate in the pathogenesis of lung damage, particularly in acute lung injury. Although megakaryocytes are not mentioned as a characteristic histologic finding associated to pulmonary injury, a few studies reveal that their number is increased in diffuse alveolar damage (DAD). In this autopsy study, we have observed a relevant number of pulmonary megakaryocytes in COVID-19 patients dying with acute lung injury (7.61 \pm 5.59 megakaryocytes per 25 high-power fields vs. $1.14 \pm 0.86$ for the control group, $p<0.05)$. We analyzed samples of 18 patients, most of whom died after prolonged disease and use of mechanical ventilation. Most patients showed advanced DAD and abnormal coagulation parameters with high levels of fibrinogen, D-dimers, and variable thrombocytopenia. For comparison, pulmonary samples from a group of 14 non-COVID-19 patients dying with DAD were reviewed. They showed similar pulmonary histopathologic findings and an increase in the number of megakaryocytes $(4 \pm 4.17 \mathrm{vs}$. $1.14 \pm 0.86$ for the control group, $p<0.05)$. Megakaryocyte count in the COVID-19 group was greater but did not reach statistical significance $(7.61 \pm 5.59$ vs. $4 \pm 4.17, p=0.063)$. Regardless of the cause, pulmonary megakaryocytes are increased in patients with DAD. Their high number seen in COVID-19 patients suggests a relation with the thrombotic events so often seen these patients. Since the lung is considered an active site of megakaryopoiesis, a prothrombotic status leading to platelet activation, aggregation and consumption may trigger a compensatory pulmonary response.
\end{abstract}

Keywords COVID-19 - Diffuse alveolar damage · Megakaryocytes · Severe acute respiratory syndrome coronavirus 2 . Thrombosis · Thrombocytopenia

Mariel F. Valdivia Mazeyra and Clara Salas contributed equally to this work.

Javier Fraga and José A. Jiménez-Heffernan share senior authorship.

This article is part of the Topical Collection on Quality in Pathology

Electronic supplementary material The online version of this article (https://doi.org/10.1007/s00428-020-02926-1) contains supplementary material, which is available to authorized users.

José A. Jiménez-Heffernan

joseantonio.jimenez@uam.es

1 Department of Pathology, University Hospital La Princesa, Madrid, Spain

2 Department of Pathology, University Hospital Puerta de Hierro, Madrid, Spain
3 Department of Anesthesia and Surgical Critical Care, University Hospital La Princesa, Madrid, Spain

4 Department of Pathology, University Hospital 12 de Octubre, Madrid, Spain

5 Department of Pathology, University Hospital del Henares, Madrid, Spain 


\section{Introduction}

Megakaryocytes (MKs) are normally present in the human lung and play a role in platelet homeostasis $[1,2]$. Originally described by Aschoff in 1893, the interest in pulmonary MKs and their platelet production has raised considerably during the last decade [1-3]. Several studies have shown that platelets participate in lung damage, particularly in acute lung injury $[2,3]$. MKs are usually not mentioned as a characteristic histopathologic finding associated to acute pulmonary injury [4-7]. However, a few studies and textbooks point out that their number is increased in the lungs of patients with diffuse alveolar damage (DAD), burns, shock, or sepsis [8-11]. Inflammatory injury to alveolar epithelium and endothelial cells, resulting in intra-alveolar edema, deposition of fibrin, and formation of microthrombi are important pathogenic mechanisms of DAD. There is experimental and clinical evidence that platelets contribute to alveolar damage and repair in acute respiratory distress syndrome (ARDS) and other forms of acute lung injury [2,3]. Similarly, abnormalities in platelet number and function influence the natural history of ARDS [2,3].

Most deaths related to severe acute respiratory syndrome coronavirus-2 (SARS-CoV-2) infection are due to pulmonary damage. Autopsy studies performed on these patients usually reveal DAD in different evolutionary phases $[7,12-36]$. Although no specific pulmonary pathologic findings have been observed, thrombosis of major vessels and microcirculation are often highlighted. It is well-known that COVID-19 patients often show prothrombotic coagulation abnormalities [37-39], being thrombocytopenia associated with a poor clinical outcome [40]. In this autopsy study, we report that pulmonary MKs are a common finding in COVID-19 patients with pulmonary damage. In addition to numerous pulmonary MKs, our patients suffered from coagulation abnormalities, including thrombocytopenia. This is not an isolated observation since other autopsy reports on COVID-19 patients mention in their microscopic descriptions an elevated number of pulmonary MKs [29-36]. A prothrombotic status leading to platelet activation, aggregation, and consumption may trigger a compensatory response of pulmonary MKs. In our work, we compare our autopsy findings with previous reports, mainly focusing of pulmonary MKs. Our series includes analytical parameters related to patient's coagulation status, including blood platelet counts. Since the lung is considered an active site of megakaryopoiesis, an increased number of pulmonary MKs suggests and supports a relation with the thrombotic events and thrombocytopenia so often seen in severe COVID-19.

\section{Methods}

\section{Patient selection}

We analyzed pulmonary autopsy specimens from 17 patients who died from respiratory failure caused by SARS-CoV-2 infection. A further infected patient who died because of end-stage malignant lymphoma (but without ARDS) and showed pulmonary COVID-19 involvement was also evaluated (case 8) (Tables 1 and 2). Two control groups, each consisting of pulmonary samples from 14 patients, were selected. The first one consisted of normal lung tissue obtained from lobectomy surgical procedures from patients with pulmonary adenocarcinoma. Eight of them were non-smokers. These specimens, from the pre-COVID-19 period, were retrieved from the pathology files of the University Hospital de la Princesa. Eleven patients were men and three women with a mean age of 68 years. The second group included 14 patients who died with DAD before the COVID-19 pandemic. Eight were men and six women with a mean age of 67 years. They were selected from the autopsy files of the University Hospital de la Princesa. During disease, these patients developed ARDS and died at the intensive care unit after mechanical ventilation treatment (Supplementary Table 1). The study was approved by the Ethics Committee of the University Hospital Gregorio Marañón, Madrid (code: EcoBCOV). All the autopsies were performed after informed consent from the closest relatives. All patients fulfilled the World Health Organization criteria for COVID-19 and presented with fever and acute respiratory symptoms, dyspnea, and hypoxia. All tested positively for SARS-CoV-2 RNA by polymerase chain reaction (PCR) assay at the time of hospital admission. In all patients' molecular tests for common respiratory viruses and bacteria disclosed negative results. Relevant clinical information from all patients was retrieved from the electronic files of the different hospital information systems.

\section{Autopsies and histologic examination}

Regarding autopsies from COVID-19 patients, 11 were complete or limited autopsy procedures performed by pathologists at the Departments of Pathology of University Hospitals Puerta de Hierro and 12 de Octubre. Both medical centers are equipped with autopsy rooms that fulfill the recommendations of the Spanish Society of Pathology for this type of autopsies. In these cases, either complete lungs or extensive samples from the different lobes were obtained. The remaining 7 patients underwent ultrasound-guided minimally invasive autopsies. These were done by anesthesiologists at the University Hospital La Princesa. Several needle core biopsies of both lungs and other organs were obtained. The procedure was done using ultrasound guidance. All tissue samples were processed routinely after $10 \%$ buffered formalin fixation for at 
Table 1 Main clinical and analytical data

\begin{tabular}{|c|c|c|}
\hline Parameter & Number of cases (when applicable) & $\%$ or range \\
\hline Sex: male-female ratio & $10-8$ & - \\
\hline Age (years) & 61 & $41-75$ \\
\hline Length of hospital stay (days) & 42 & $22-73$ \\
\hline Days on mechanical ventilation & 31 & $13-56$ \\
\hline \multicolumn{3}{|l|}{ Comorbidities } \\
\hline Hypertension & 8 & $44 \%$ \\
\hline Diabetes mellitus & 8 & $44 \%$ \\
\hline Dyslipidemia & 7 & $39 \%$ \\
\hline Smoker or previous smoker & 6 & $33 \%$ \\
\hline Malignancy & 6 & $33 \%$ \\
\hline Hyperuricemia or gout & 2 & $11 \%$ \\
\hline \multicolumn{3}{|l|}{ Initial clinical presentation } \\
\hline Fever & 16 & $44 \%$ \\
\hline Cough & 8 & $89 \%$ \\
\hline Dyspnea/tachypnea & 8 & $44 \%$ \\
\hline Diarrhea & 6 & $33 \%$ \\
\hline \multicolumn{3}{|l|}{ Radiological findings } \\
\hline Ground-glass infiltrates & 17 & $94 \%$ \\
\hline \multicolumn{3}{|c|}{ Mean laboratory findings during last week before death } \\
\hline Lymphopenia $\left(<1.0 \times 10^{-9} / \mathrm{L}\right)$ & 14 & $78 \%$ \\
\hline Low platelets $\left(<150 \times 10^{-9} / \mathrm{L}\right)$ & 9 & $50 \%$ \\
\hline High D-dimers $(>0.50 \mu \mathrm{g} / \mathrm{mL})$ & 18 & $100 \%$ \\
\hline High fibrinogen (> $400 \mathrm{mg} / \mathrm{mL}$ ) & 15 & $83 \%$ \\
\hline Prolonged INR (> 1.30) & 4 & $22 \%$ \\
\hline Treatment with heparin & 18 & $100 \%$ \\
\hline
\end{tabular}

INR, international normalized ratio

least $48 \mathrm{~h}$. The normal lung tissue was obtained from lobectomy surgical specimens. Normal samples located away from the tumoral area are always included for study, and these were selected for MK counting. Areas of emphysema that could have resulted in a low count were avoided in all six smokers. Autopsies from the non-COVID-19 patients with DAD were routinely performed, and extensive pulmonary tissue from the different lobes was available for study.

Initial histologic evaluation of the COVID-19 samples was independently done by pathologists from each hospital. Afterwards, they were reviewed together by two expert pulmonary pathologists (CS, JAJH). After the initial histologic analysis, further examination was made putting emphasis on the detection of thrombi and MKs. Pulmonary MKs were quantified according to previously published methodology $[8,35]$. A high value was defined as the presence of more than four MKs per 25 high-power fields $(\mathrm{hpf})(\times 40)$. We further stratified MK counting: absent or rare $(\leq 4 / 25 \mathrm{hpf})$, slightly increased ( $>4-7 / 25 \mathrm{hpf})$, moderate (8-11/25 hpf), and abundant ( $\geq 12 \mathrm{hpf}$. Except for $\leq 4 / 25 \mathrm{hpf}$ that is considered a normal value for pulmonary MKs $[8,35]$, the remaining cut- off values were arbitrarily established. As mentioned by Carsana et al. [35], each sample was initially inspected at low magnification to identify areas in which MKs were most easily recognizable and then were counted in these areas. MK counting was done simultaneously by three pathologists using hematoxylin-eosin-stained slides. MK morphology is so characteristic that mature cells are easily recognizable. Nevertheless, CD61 immunoexpression was used for confirmation. The latter can also be expressed by platelets and platelet-rich thrombi, so correlation with morphology is essential to avoid errors. In most COVID-19 cases, MKs were a remarkable finding, and even in core needle biopsies, quantification was easy. As seen in Fig, 1, in many cases, there were areas with three or more MKs in a single high-power microscopic field. Apart from MKs, no other myeloid or erythroid bone marrow cells were observed. Several other relevant histologic parameters were also evaluated (Table 2). For the two control groups, the same counting method was applied. Similar histologic parameters were evaluated in specimens from non-COVID-19 patients with DAD (Supplementary Table 1). 
Table 2 Main pulmonary pathologic findings

\begin{tabular}{|c|c|c|c|c|c|c|c|}
\hline Case & $\begin{array}{l}\text { Increased } \\
\text { megakaryocytes }\end{array}$ & $\begin{array}{l}\text { Predominant DAD } \\
\text { phase }\end{array}$ & Alveolar fibrin & Fibrosis & Thrombi & MGCs & Other \\
\hline 1 & Yes $(8 / 25$ hpf $)$ & Fibroproliferative & Residual HM & Interstitial & + & + & $\begin{array}{l}\text { Subpleural cysts, osseous } \\
\text { metaplasia, BP foci }\end{array}$ \\
\hline 2 & No & Fibroproliferative & No & Interstitial & - & + & $\begin{array}{l}\text { Pulmonary infarct, osseous } \\
\text { metaplasia }\end{array}$ \\
\hline 3 & Yes (13/25 hpf) & Proliferative & Residual HM & Interstitial & - & + & Osseous metaplasia \\
\hline 4 & Yes $(8 / 25 \mathrm{hpf})$ & Fibroproliferative & No & Doughnut-like and interstitial & - & + & - \\
\hline 5 & Yes (15/25 hpf) & Fibrotic & Residual HM & Interstitial & + & + & Osseous metaplasia \\
\hline 6 & Yes $(6 / 25 \mathrm{hpf})$ & Fibrotic & No & Interstitial, doughnut-like & + & + & $\begin{array}{l}\text { Subpleural cysts, osseous } \\
\text { metaplasia }\end{array}$ \\
\hline 7 & No & Fibrotic & Fibrin "balls" & Interstitial & - & - & Subpleural cysts \\
\hline $8^{\mathrm{a}}$ & No & - & Focal HM formation & No & - & - & Prominent edema \\
\hline 9 & No & Fibrotic & Fibrin "balls" & Interstitial, doughnut-like & - & + & - \\
\hline 10 & Yes (10/25 hpf) & Fibroproliferative & Fibrin "balls" & Interstitial & + & - & $\begin{array}{l}\text { Osseous metaplasia corpora } \\
\text { amylacea }\end{array}$ \\
\hline 11 & Yes (18/25 hpf) & Fibrotic & Fibrin "balls" & Interstitial & + & + & Subpleural cysts \\
\hline 12 & Yes $(5 / 25 \mathrm{hpf})$ & Fibroproliferative & Residual HM & Interstitial & + & + & Corpora amylacea, BP foci \\
\hline 13 & Yes $(6 / 25 \mathrm{hpf})$ & Fibrotic & No & Interstitial & - & + & Osseous metaplasia \\
\hline 14 & No & Exudative & Numerous HM & No & - & - & - \\
\hline 15 & Yes $(8 / 25 \mathrm{hpf})$ & Proliferative & Fibrin "balls" & Minimal interstitial & - & - & Corpora amylacea, BP foci \\
\hline 16 & Yes (8/25 hpf) & Fibrotic & No & Organizing pneumonia & - & - & - \\
\hline 17 & Yes $(15 / 25 \mathrm{hpf})$ & Fibroproliferative & No & Interstitial & - & + & - \\
\hline 18 & Yes (13/25 hpf) & Fibroproliferative & Fibrin "balls", HM & Interstitial, doughnut-like & - & + & - \\
\hline
\end{tabular}

DAD, diffuse alveolar damage; MGCs, multinucleated giant cells; hpf, high-power fields; HM, hyaline membranes; BP, bronchopneumonia foci

${ }^{\text {a }}$ Only patient who received no mechanical ventilation

\section{Statistical analysis}

The mean and standard deviation of the MK counts were calculated for each group of patients. The differences among the groups were analyzed with the Kruskal-Wallis nonparametric test. Values of $p<0.05$ were considered significant. Differences between groups were ascertained by performing comparison with the Mann-Whitney $U$ test. Within the COVID-19 group, Spearman's non-parametric test was used to compare the number of MKs with quantitative variables (platelets, D-dimers, fibrinogen). Qualitative variables (DAD phase, thrombosis) were compared using the Mann-Whitney $U$ test.

Data were evaluated using SPSS 21.0.

\section{Results}

\section{Clinical findings}

Table 1 presents the main clinical data of the eighteen COVID-19 patients evaluated. The patients were 10 men and 8 women, with a mean age of 61 years (range: 41-75).
Regarding comorbidities, eight had hypertension, eight had diabetes, seven had dyslipidemia, six had current or past malignancies, six were smokers, and two had hyperuricemia or gout. The most relevant initial symptoms were fever, cough, dyspnea or tachypnea, and diarrhea. At the time of hospitalization, image studies showed bilateral ground-glass infiltrates in seventeen patients. They were first admitted on a regular medical ward and afterwards were derived to an intermediate medical ward or intensive care unit, according to the severity of disease. Except for one patient (case 8) who died of endstage angioimmunoblastic T-cell lymphoma, all patients were treated with mechanical ventilation. The mean hospital stay was 42 days (range: 22 to 73 ), and the time on mechanical ventilation was 31 days (range: 13 to 56). Laboratory findings during the last week before death are summarized in Table 1 . Fourteen patients had lymphopenia (lymphocyte count $<1.0 \times$ $10^{-9} / \mathrm{L}$ ). Abnormal coagulation values were seen in the majority of patients: nine $(50 \%)$ had thrombocytopenia $(<150$ platelets $\left.\times 10^{-9} / \mathrm{L}\right)$, eighteen $(100 \%)$ had high D-dimers $(>$ $0.50 \mu \mathrm{g} / \mathrm{mL}$ ), and fifteen $(83 \%)$ had high fibrinogen ( $>400$ $\mathrm{mg} / \mathrm{mL}$ ). Rarely, prolonged levels of international normalized ratio (INR) were observed (4 patients, 22\%). All patients were treated with heparin. 


\section{Pulmonary histologic findings}

Pulmonary tissue from the normal control group revealed no abnormalities. In this group, MK count revealed similar values in the different samples: $1.14 \pm 0.86$ per $25 \mathrm{hpf}$. The maximum value in this group was a single case with $3 / 25 \mathrm{hpf}$.

Main histologic findings from COVID-19 patients are summarized in Table 2. Except for patient 8 , all cases showed histologic evidence of DAD. The predominant lung pattern was DAD in fibroproliferative or fibrotic stages. The most common pattern of fibrosis was interstitial with occasional doughnut-like areas. One case showed extensive areas of organizing pneumonia with numerous intraalveolar fibroblastic plugs. Intermixed with the fibrotic areas, most cases had alveolar septal congestion and varying degrees of intraalveolar hemorrhage, fibrin, edema, and desquamation of pneumocytes. Hyperplastic pneumocytes, many of which showed dense cytoplasm and large nuclei with prominent nucleoli, were also a constant finding. Almost all samples had foci of squamous metaplasia near bronchial or bronchiolar structures. In one case, Kuhn's hyaline was present in the cytoplasm of reactive pneumocytes. We observed no viral inclusions. Multinucleated giant cells were present in 12 of the 18 cases. Three cases had associated areas of bronchopneumonia with numerous neutrophils and focal necrosis. Subpleural fibrotic cysts, most probably due to invasive mechanical ventilation, were seen in five cases. Other findings were alveolar corpora amylacea and focal lesions of osseous metaplasia. In patient 8 , no established lesions of DAD were present. The lungs showed intense edema, some degree of pneumocyte hyperplasia, and focal presence of alveolar fibrin. Thirteen of the 18 patients (72.2\%) analyzed showed an increased number of MKs, as previously defined ( $>4 / 25$ highpower fields) (Figs. 1,2). In patients 2, 7, and 9, MKs were present, but their number was below the established threshold. In patient 14, despite a long clinical course and use of mechanical ventilation, the core needle tissue sample only revealed areas of exudative DAD with numerous hyaline membranes and no fibrosis or relevant number of MKs. We believe that it may be due to a sampling problem and that the more consolidated pulmonary areas were not biopsied. In three cases, the increase in MK number was slight (5-7/25 hpf), in five moderate (8-11/25 hpf), and in five abundant $(\geq 12 /$ $25 \mathrm{hpf}$ ). The mean and standard deviation of the pulmonary MK count in COVID-19 patients were $7.61 \pm 5.59$. Thrombi were an evident finding in six cases (Fig. 2). Morphologic detection of small thrombi in the microcirculation can be very difficult, and we only considered those cases in which concordance among pathologists was present. It is important to note that all patients were receiving anticoagulant therapy with heparin. Five of the cases in which thrombi were detected corresponded to large pulmonary tissue samples from "open" autopsy procedures. In contrast, thrombi were present in only one of the samples obtained using ultrasound-guided minimally invasive procedures.

Histologic findings in the non-COVID-19 patients with DAD were like those described for COVID-19 patients (Supplementary Table 1). For this group, the mean and standard deviation of the MK count were $4 \pm 4.17$ per $25 \mathrm{hpf}$. Significant differences in the number of MKs were observed between the normal control group and both $\mathrm{DAD}$ groups with and without COVID-19 (1.14 $\pm 0.86,7.61 \pm 5.59$, and $4 \pm$ 4.17, respectively, $p<0.05$ ). COVID-19 samples showed more MKs than non-COVID-19 ones, but differences did not reach statistical significance $(p=0.063)$. Within the COVID-19 patient group, no differences were observed between the number of MKs and platelet count, D-dimers, fibrinogen, presence of thrombosis, DAD phase, or sample type (regular autopsy vs trucut biopsies).

\section{Discussion}

Pulmonary histopathologic changes related to ARDS are usually similar regardless of its etiology [4-7]. This observation can be extended to cases caused by SARS-CoV-2 infection [7]. In 2007, Mandal et al. reported abnormalities in platelet homeostasis, including an increase in the number of pulmonary MKs in patients with DAD [8]. In their series of 21 patients, those with thrombocytopenia had a worse prognosis. In this autopsy study, we have shown that MKs are a common finding in the lungs of COVID-19 patients dying with DAD. Our patients showed abnormal coagulation parameters with high levels of fibrinogen, D-dimers, and variable thrombocytopenia. As expected, the group of non-COVID-19 patients with DAD also showed an increased MK number. MKs were more abundant in the COVID-19 group, but differences did not reach statistical significance.

Numerous autopsy studies describing patients dying from COVID-19 have been published [7, 12-36]. In seven of them, pulmonary MKs are mentioned in the autopsy reports. Three of these studies relate their presence to the hypercoagulability status so characteristic of these patients $[29,30,36]$. They describe general autopsy findings and do not quantify MKs or include a correlation with coagulation parameters. Four other reports refer to pulmonary MKs as a relevant finding [31-35]. Carsana et al. quantified them revealing an increased number in 33 of their 38 patients [35]. Similarly, these reports describe general findings, and the presence of MKs is not further commented. In the remaining autopsy studies, including a review article, there are no references to MKs [12-28, 41]. Various reasons could explain this absence. As mentioned before, MKs are not a histological variable usually associated to DAD, so pathologists may not be tempted to perform a specific search or to report them. Lung MKs are rare, and even if their number is increased, the counts in 

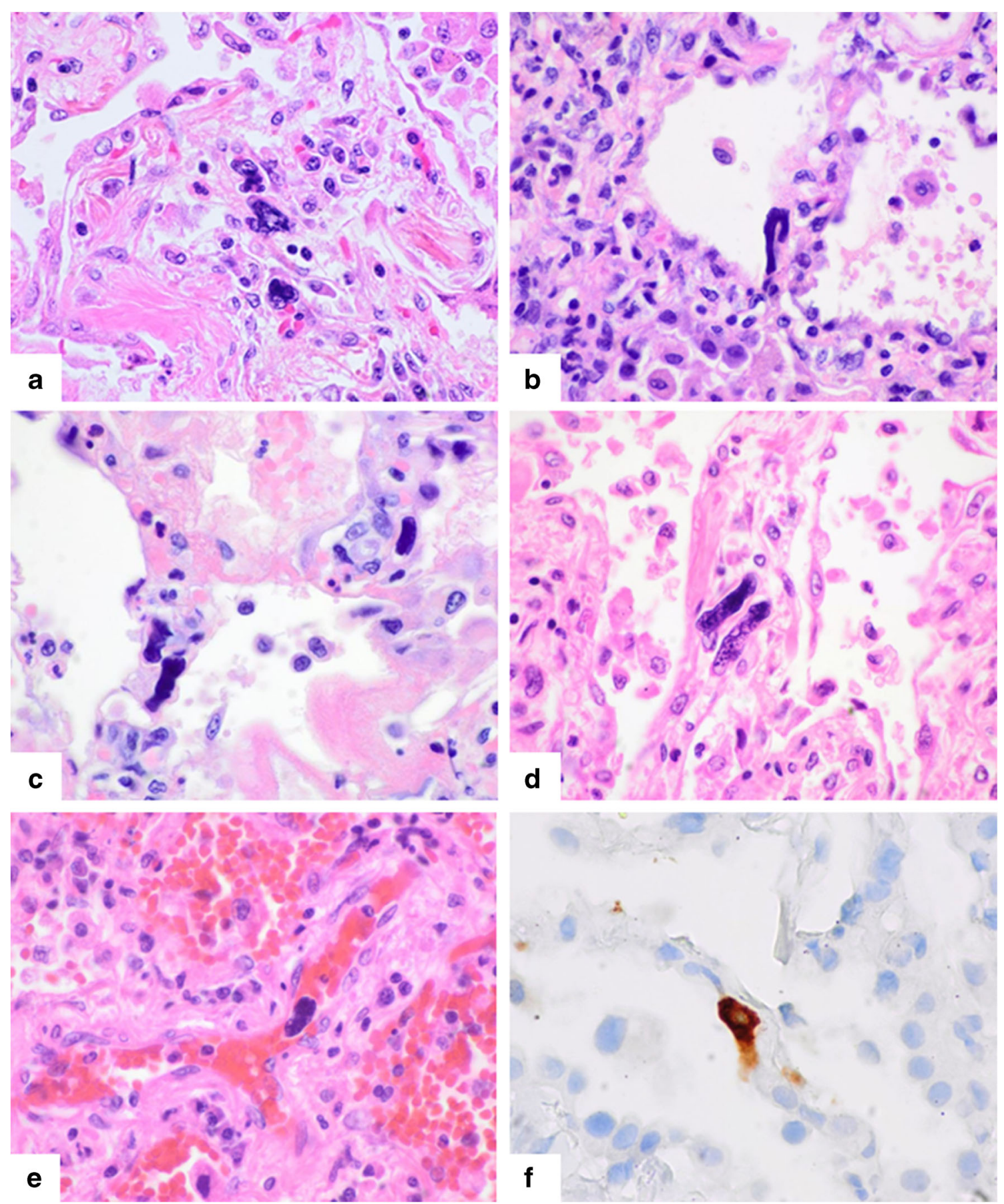

Fig. 1 (a-d) Pulmonary histologic sections from different COVID-19 patients with diffuse alveolar damage showing a relevant increase in the number of megakaryocytes. In contrast to those of the bone marrow, pulmonary megakaryocytes often show an elongated nuclear

absolute terms can still be low. If a specific search is not performed, MKs can easily be overlooked. Because MKs are trapped in the pulmonary microcirculation, their morphology differs from that seen in bone marrow. Pulmonary MKs show less cytoplasm and fewer nuclear lobulations. The nucleus tends to be elongated as if adapted to the vessel diameter. Although hematoxylin and eosin stain permits a confident

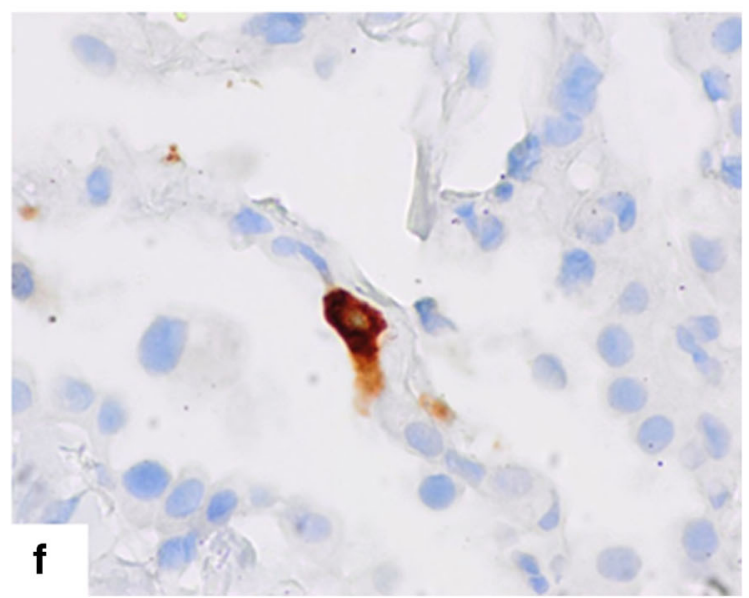

morphology, scarce cytoplasm, and few nuclear lobulations (hematoxylin-eosin (HE), $\times 600$ ). (e) A megakaryocyte is visible within the lumen of a larger vessel (HE, $\times 600)$. (f) As expected, megakaryocytes showed immunoexpression of CD61 (immunoperoxidase, $\times 600$ )

recognition of MKs, their detection can be facilitated by immunohistochemical analysis. CD61 is expressed by MKs, but it can also be expressed by platelets and platelet-rich thrombi [42]. Therefore, to avoid overcounting, a close correlation between histology and immunohistochemistry is advisable. Another possible reason for the lack of references to MKs is that some reports describe patients with early or incidental 


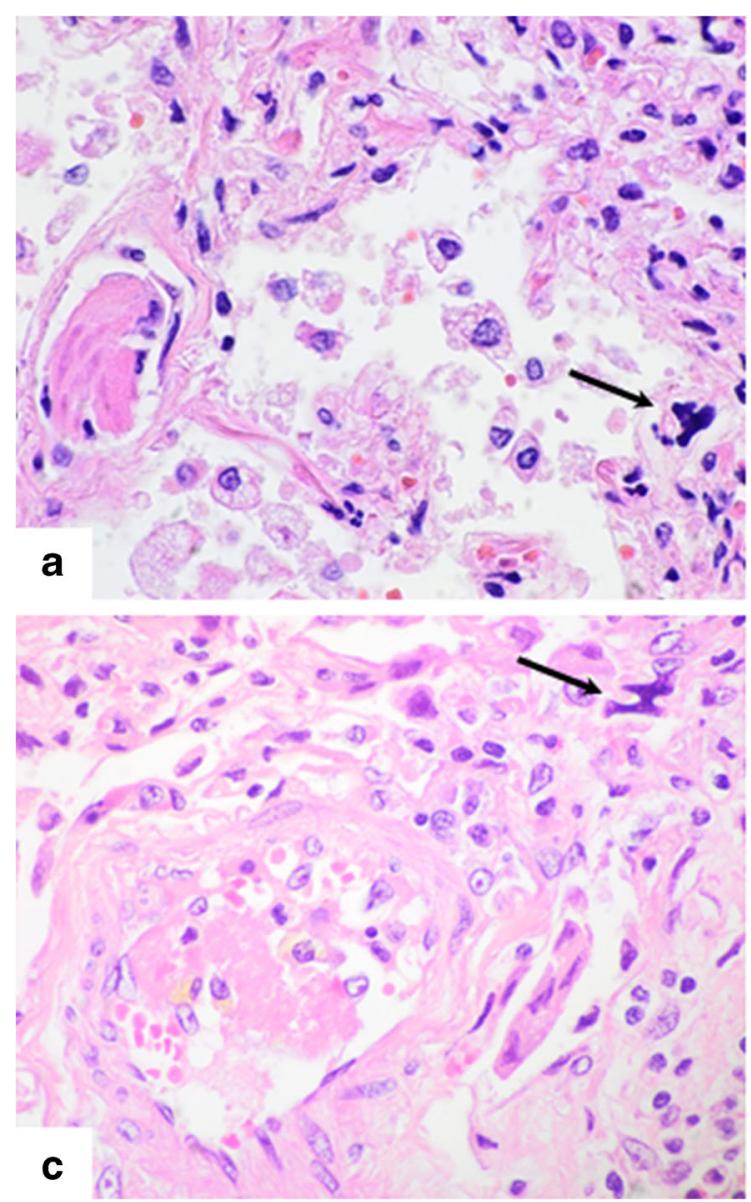

Fig. 2 Pulmonary histologic samples from four COVID-19 patients showing thrombosis and megakaryocytes. (a) An intravascular thrombus is visible at the left of the image. In the same high-power field, a megakaryocyte is clearly visible (arrow) (HE, $\times 600)$. (b) The image reveals an

pulmonary lesions but no ARDS $[19,20]$. In this sense, one of our patients without MKs had pulmonary edema but no definitive histologic findings of DAD. This patient died because of end-stage malignant lymphoma without ARDS. Other reports describing deaths in non-hospitalized patients focus on macroscopic findings, mainly thromboembolic events, and although pulmonary histologic findings are mentioned, they are not described in depth. Size tissue sample is another potential limiting factor for the detection of MKs. However, it should be noted that we have easily found them in trucut biopsies. Similarly, the previously mentioned study by Duarte-Neto et al. [29] is based on trucut biopsies. Finally, not all patients showed an increase number of MKs. Our series and that of Carsana et al. [35] revealed no significant number of MKs in 27.8 and $13.2 \%$ of the patients, respectively. For quantification of MKs, the studies by Mandal et al. [8] and Carsana et al. [35] used CD61 immunoexpression. We preferred to count them directly using hematoxylin and eosin staining. CD61 immunoexpression permits the detection of small immature MKs that are difficult to see by routine staining methods and may account for some of the differences

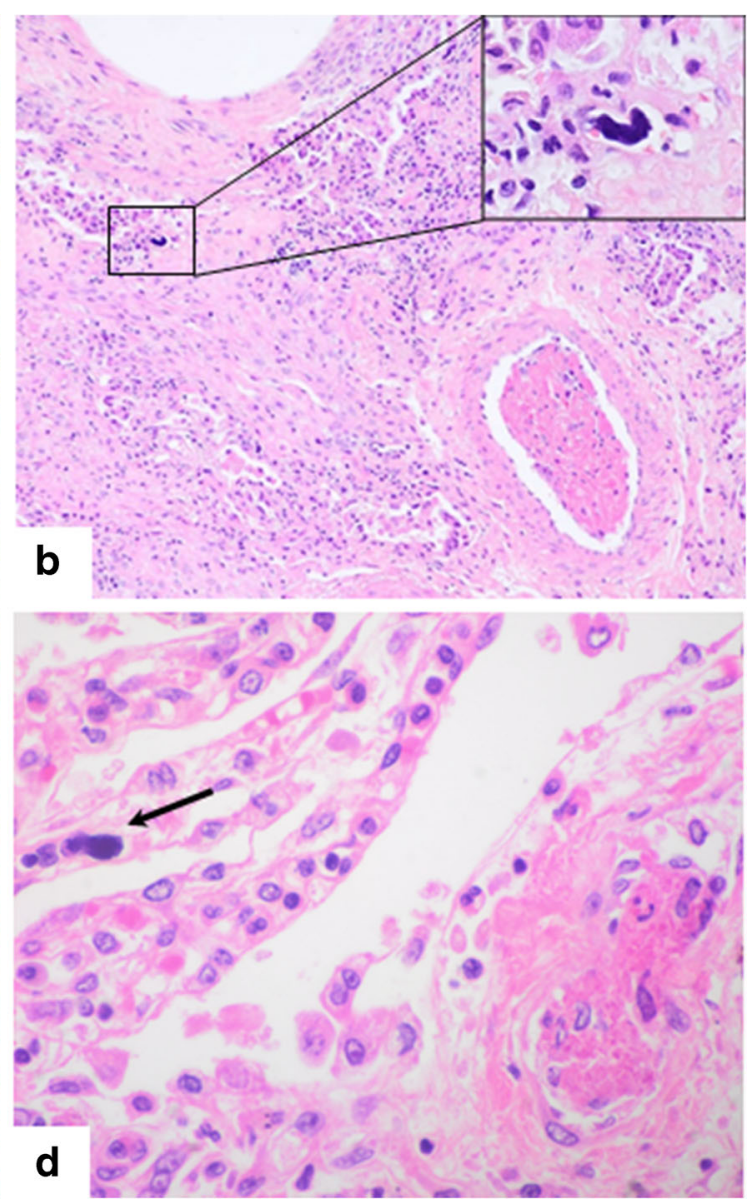

intravascular thrombus at a pulmonary artery (lower right) $(\mathrm{HE}, \times 200)$. The inset highlights the presence of a megakaryocyte in the vicinity. (c,d) In each high-power image, intravascular thrombi and megakaryocytes (arrows) are present $(\mathrm{HE}, \times 600)$

observed in the normal control group of Mandal et al. [8] and ours ( $3 \pm 1$ vs $1.14 \pm 0.86$, respectively). Routine stains, however, avoids overcounting microthrombi as MKs, a relevant problem since they are common in DAD regardless of its cause. This different methodology may explain some of the differences seen in the absolute number of MKs. Nevertheless, the three studies coincide in the increase of pulmonary MKs in DAD, including COVID-19 patients.

In addition to SARS-CoV-2, two other members of the coronavirus family, SARS-CoV and Middle East respiratory syndrome (MERS-CoV), cause pulmonary injury. The autopsy studies performed describe pulmonary damage consistent with different phases of DAD but do not mention or illustrate pulmonary MKs [43-48]. Their absence could be attributed to a greater tendency to thrombotic events in COVID-19 patients, but similar procoagulation abnormalities have been described in SARS and MERS [37].

Regarding pathogenesis, the observed increment in pulmonary MKs may obey to a compensatory response. It is wellknown that such responses occur in the bone marrow because of thrombocytopenia. Knowing that the lung is a normal site 
of megakaryopoiesis, it is tempting to believe that the increased number of MKs observed in our patients is, in part, secondary to thrombotic events, platelet activation, aggregation, and consumption. In this sense, a recent study shows that COVID-19 significantly alters platelet gene expression, triggering a robust platelet hyperreactivity [38]. In addition, COVID-19 patients have elevated plasma levels of thrombopoietin, a well-known megakaryocyte growth factor [38]. In addition to DAD-related thrombosis of the pulmonary microcirculation, COVID-19 patients have a systemic procoagulatory status. Finally, another interesting aspect of MK biology concerns its fibrotic capacity. MKs produce transforming growth factor-beta and participate in bone marrow fibrosis [49]. A similar pro-fibrotic capacity has been demonstrated for pulmonary MKs in an experimental model of lung fibrosis [50]. Precisely, diffuse lung fibrosis is one of the greatest complications of ARDS. Therefore, pulmonary MKs must be considered as potential contributors to fibrosis in this precise context.

\section{Conclusion}

This study shows that pulmonary MKs are increased in patients with DAD, including those with SARS-CoV-2 infection. There are still few pathologic studies relating MKs and acute pulmonary injury, but it seems that such increase is a characteristic of DAD regardless of its cause. The relative abundance of pulmonary MKs in COVID-19 patients may reflect the prothrombotic tendency seen in these patients. Future studies of patients dying with acute pulmonary injury should include pulmonary MKs as a histologic variable of interest. Similarly, the review of previous autopsy studies on COVID-19 patients looking for pulmonary MKs may help us to further define their role in the pathogeny of pulmonary damage.

Authors' contributions Mariel F. Valdivia Mazeyra: study design, data analysis, literature review, and writing. Clara Salas: study design, data analysis, literature review, and editing of text. Jesús M. Nieves-Alonso: ultrasonographic autopsy performance and data analysis. Luz MartínFragueiro: data analysis and review of histopathology. Carmen Bárcena: autopsy performance, review of histopathology, data analysis, and editing of the text. Patricia Muñoz-Hernandez: review of histopathology and literature review. Karen Villar: ultrasonographic autopsy performance and review of histopathology. Javier Martín-López: data analysis and review of histopathology. Fernando Ramasco-Rueda: ultrasonographic autopsy performance, and data analysis. Javier Fraga: study design, data analysis, review of histopathology, and editing of the text. José A. Jiménez-Heffernan: study design, writing, data analysis, and review of histopathology.

Funding The authors have no funding sources to declare.

Availability of data All data and material are available.

\section{Compliance with ethical standards}

Conflicts of interest The authors declare that they have no conflict of interest.

Ethical approval The study protocol was approved by the Ethics Committee of University Hospital Gregorio Marañón, Madrid, Spain (code: EcoBCOV).

Consent to participate/for publication For all patients, informed consents were obtained from closest relatives.

Code availability (software application or custom code) Not applicable.

\section{References}

1. Lefrançais E, Ortiz-Muñoz G, Caudrillier A, Mallavia B, Liu F, Sayah DM, Thornton EE, Headley MB, David T, Coughlin SR, Krummel MF, Leavitt AD, Passegué E, Looney MR (2017) The lung is a site of platelet biogenesis and a reservoir for haematopoietic progenitors. Nature 544:105-109. https://doi.org/ 10.1038/nature21706

2. Washington AV, Esponda O, Gibson A (2020) Platelet biology of the rapidly failing lung. Br J Haematol 188:641-651. https://doi. org/10.1111/bjh.16315

3. Yadav H, Kor DJ (2015) Platelets in the pathogenesis of acute respiratory distress syndrome. Am J Phys Lung Cell Mol Phys 309:L915-L923. https://doi.org/10.1152/ajplung.00266.2015

4. Cheung O-Y, Graziano P, Smith ML (2018) Acute lung injury. In: Leslie KO, Wick MR (eds) Practical pulmonary pathology: a diagnostic approach, 3rd edn. Elsevier, Philadelphia, pp 125-146

5. Hughes KT, Beasley MB (2017) Pulmonary manifestations of acute lung injury: more than just diffuse alveolar damage. Arch Pathol Lab Med 141:916-922. https://doi.org/10.5858/arpa.20160342-RA

6. Castro CY (2006) ARDS and diffuse alveolar damage: a pathologist's perspective. Semin Thorac Cardiovasc Surg 18:13-19. https://doi.org/10.1053/j.semtcvs.2006.02.001

7. Konopka KE, Nguyen T, Jentzen JM et al (2020) Diffuse alveolar damage (DAD) from coronavirus disease 2019 infection is morphologically indistinguishable from other causes of DAD. Histopathology. https://doi.org/10.1111/his.14180

8. Mandal RV, Mark EJ, Kradin RL (2007) Megakaryocytes and platelet homeostasis in diffuse alveolar damage. Exp Mol Pathol 83:327-331. https://doi.org/10.1016/j.yexmp.2007.08.005

9. Wells S, Sissons M, Hasleton PS (1984) Quantitation of pulmonary megakaryocytes and fibrin thrombi in patients dying from burns. Histopathology 8:517-527. https://doi.org/10.1111/j.1365-2559. 1984.tb02361.x

10. Corrin B, Nicholson AG (2011) Acute alveolar injury and repair. In: Pathology of the lungs, 3rd edn. Churchill Livingstone Elsevier, Edinburgh, pp 135-154

11. Colby TV, Leslie KO, Yousem SA (2007) Lungs. In: Mills SE (ed) Histology for pathologists, 3rd edn. Lippincott Williams and Wilkins, Philadelphia, pp 473-504

12. Barton LM, Duval EJ, Stroberg E, Ghosh S, Mukhopadhyay S (2020) COVID-19 Autopsies, Oklahoma, USA. Am J Clin Pathol 153:725-733. https://doi.org/10.1093/ajcp/aqaa062

13. Adachi T, Chong J-M, Nakajima N, Sano M, Yamazaki J, Miyamoto I, Nishioka H, Akita H, Sato Y, Kataoka M, Katano H, Tobiume M, Sekizuka T, Itokawa K, Kuroda M, Suzuki T (2020) Clinicopathologic and immunohistochemical findings from 
autopsy of patient with COVID-19, Japan. Emerg Infect Dis 26: 2157-2161. https://doi.org/10.3201/eid2609.201353

14. Yan L, Mir M, Sanchez P et al (2020) COVID-19 in a Hispanic woman: autopsy report with clinical pathological correlation. Arch Pathol Lab Med. https://doi.org/10.5858/arpa.2020-0217-SA

15. Konopka KE, Wilson A, Myers JL (2020) Postmortem lung findings in an asthmatic patient with coronavirus disease 2019. Chest S0012369220307753:e99-e101. https://doi.org/10.1016/j.chest. 2020.04.032

16. Wichmann D, Sperhake J-P, Lütgehetmann M, Steurer S, Edler C, Heinemann A, Heinrich F, Mushumba H, Kniep I, Schröder AS, Burdelski C, de Heer G, Nierhaus A, Frings D, Pfefferle S, Becker $\mathrm{H}$, Bredereke-Wiedling $\mathrm{H}$, de Weerth A, Paschen HR, Sheikhzadeh-Eggers S, Stang A, Schmiedel S, Bokemeyer C, Addo MM, Aepfelbacher M, Püschel K, Kluge S (2020) Autopsy findings and venous thromboembolism in patients with COVID-19: a prospective cohort study. Ann Intern Med 173:M20-M2003. https://doi.org/10.7326/M20-2003

17. Ackermann M, Verleden SE, Kuehnel M et al (2020) Pulmonary vascular endothelialitis, thrombosis, and angiogenesis in COVID19. N Engl J Med. https://doi.org/10.1056/NEJMoa2015432

18. Tian S, Xiong Y, Liu H, Niu L, Guo J, Liao M, Xiao SY (2020) Pathological study of the 2019 novel coronavirus disease (COVID19) through postmortem core biopsies. Mod Pathol 33:1007-1014. https://doi.org/10.1038/s41379-020-0536-x

19. Tian S, Hu W, Niu L, Liu H, Xu H, Xiao SY (2020) Pulmonary pathology of early-phase 2019 novel coronavirus (COVID-19) pneumonia in two patients with lung cancer. J Thorac Oncol 15: 700-704. https://doi.org/10.1016/j.jtho.2020.02.010

20. Pernazza A, Mancini M, Rullo E, Bassi M, de Giacomo T, Rocca CD, d'Amati G (2020) Early histologic findings of pulmonary SARS-CoV-2 infection detected in a surgical specimen. Virchows Arch. https://doi.org/10.1007/s00428-020-02829-1

21. Magro C, Mulvey JJ, Berlin D, Nuovo G, Salvatore S, Harp J, Baxter-Stoltzfus A, Laurence J (2020) Complement associated microvascular injury and thrombosis in the pathogenesis of severe COVID-19 infection: a report of five cases. Transl Res 220:1-13. https://doi.org/10.1016/j.trsl.2020.04.007

22. Menter T, Haslbauer JD, Nienhold R et al (2020) Post-mortem examination of COVID19 patients reveals diffuse alveolar damage with severe capillary congestion and variegated findings of lungs and other organs suggesting vascular dysfunction. Histopathology. https://doi.org/10.1111/his.14134

23. Lax SF, Skok K, Zechner P, Kessler HH, Kaufmann N, Koelblinger C, Vander K, Bargfrieder U, Trauner M (2020) Pulmonary arterial thrombosis in COVID-19 with fatal outcome: results from a prospective, single-center, clinicopathologic case series. Ann Intern Med 173:M20-M2566. https://doi.org/10.7326/M20-2566

24. Schaller T, Hirschbühl K, Burkhardt K, Braun G, Trepel M, Märkl B, Claus R (2020) Postmortem examination of patients with COVID-19. JAMA 323:2518. https://doi.org/10.1001/jama.2020. 8907

25. Sekulic M, Harper H, Nezami BG et al (2020) Molecular detection of SARS-CoV-2 infection in FFPE samples and histopathologic findings in fatal SARS-CoV-2 cases. Am J Clin Pathol. https:// doi.org/10.1093/ajcp/aqaa091

26. Scendoni R, Marchesani F, Cannovo N, Fedeli P, Cingolani M (2020) Histopathology of COVID-19 pneumonia in two non-oncological, non-hospitalised cases as a reliable diagnostic benchmark. Diagn Pathol 15:73. https://doi.org/10.1186/s13000-020-00990-4

27. Martines RB, Ritter JM, Matkovic E, Gary J, Bollweg BC, Bullock H, Goldsmith CS, Silva-Flannery L, Seixas JN, Reagan-Steiner S, Uyeki T, Denison A, Bhatnagar J, Shieh WJ, Zaki SR, COVID-19 Pathology Working Group (2020) Pathology and pathogenesis of SARS-CoV-2 associated with fatal coronavirus disease, United
States. Emerg Infect Dis 26:2005-2015. https://doi.org/10.3201/ eid2609.202095

28. Bösmüller H, Traxler S, Bitzer M, Häberle H, Raiser W, Nann D, Frauenfeld L, Vogelsberg A, Klingel K, Fend F (2020) The evolution of pulmonary pathology in fatal COVID-19 disease: an autopsy study with clinical correlation. Virchows Arch 477:349-357. https://doi.org/10.1007/s00428-020-02881-x

29. Nunes Duarte-Neto A, de Almeida Monteiro RA, da Silva LFF et al (2020) Pulmonary and systemic involvement of COVID-19 assessed by ultrasound-guided minimally invasive autopsy. Histopathology. https://doi.org/10.1111/his.14160

30. Fox SE, Akmatbekov A, Harbert JL, Li G, Quincy Brown J, Vander Heide RS (2020) Pulmonary and cardiac pathology in African American patients with COVID-19: an autopsy series from New Orleans. Lancet Respir Med S2213260020302435:681-686. https://doi.org/10.1016/S2213-2600(20)30243-5

31. Buja LM, Wolf DA, Zhao B, Akkanti B, McDonald M, Lelenwa L, Reilly N, Ottaviani G, Elghetany MT, Trujillo DO, Aisenberg GM, Madjid M, Kar B (2020) The emerging spectrum of cardiopulmonary pathology of the coronavirus disease 2019 (COVID-19): report of 3 autopsies from Houston, Texas, and review of autopsy findings from other United States cities. Cardiovasc Pathol 48: 107233. https://doi.org/10.1016/j.carpath.2020.107233

32. Aguiar D, Lobrinus JA, Schibler M, Fracasso T, Lardi C (2020) Inside the lungs of COVID-19 disease. Int J Legal Med 134:12711274. https://doi.org/10.1007/s00414-020-02318-9

33. Suess C, Hausmann R (2020) Gross and histopathological pulmonary findings in a COVID-19 associated death during self-isolation. Int J Legal Med 134:1285-1290. https://doi.org/10.1007/s00414020-02319-8

34. Edler C, Schröder AS, Aepfelbacher M, Fitzek A, Heinemann A, Heinrich F, Klein A, Langenwalder F, Lütgehetmann M, Meißner K, Püschel K, Schädler J, Steurer S, Mushumba H, Sperhake JP (2020) Dying with SARS-CoV-2 infection - an autopsy study of the first consecutive 80 cases in Hamburg, Germany. Int J Legal Med 134:1275-1284. https://doi.org/10.1007/s00414-020-02317w

35. Carsana L, Sonzogni A, Nasr A, Rossi RS, Pellegrinelli A, Zerbi P, Rech R, Colombo R, Antinori S, Corbellino M, Galli M, Catena E, Tosoni A, Gianatti A, Nebuloni M (2020) Pulmonary post-mortem findings in a series of COVID-19 cases from northern Italy: a twocentre descriptive study. Lancet Infect Dis S1473309920304345. https://doi.org/10.1016/S1473-3099(20)30434-5

36. Tombolini A, Scendoni R (2020) SARS-CoV-2-related deaths in routine forensic autopsy practice: histopathological patterns. Int $\mathrm{J}$ Legal Med. https://doi.org/10.1007/s00414-020-02354-5

37. Giannis D, Ziogas IA, Gianni P (2020) Coagulation disorders in coronavirus infected patients: COVID-19, SARS-CoV-1, MERS$\mathrm{CoV}$ and lessons from the past. J Clin Virol 127:104362. https://doi. org/10.1016/j.jcv.2020.104362

38. Manne BK, Denorme F, Middleton EA (2020) Platelet gene expression and function in COVID-19 patients. Blood. https://doi.org/10. 1182/blood.2020007214

39. Levi M, Thachil J, Iba T, Levy JH (2020) Coagulation abnormalities and thrombosis in patients with COVID-19. Lancet Haematol 7:e438-e440. https://doi.org/10.1016/S2352-3026(20)30145-9

40. Maquet J, Lafaurie M, Sommet A et al (2020) Thrombocytopenia is independently associated with poor outcome in patients hospitalized for COVID-19. Br J Haematol. https://doi.org/10.1111/bjh. 16950

41. Polak SB, Van Gool IC, Cohen D, von der Thüsen JH, van Paassen $\mathrm{J}$ (2020) A systematic review of pathological findings in COVID19: a pathophysiological timeline and possible mechanisms of disease progression. Mod Pathol. https://doi.org/10.1038/s41379-0200603-3 
42. Burke AP, Mont E, Kolodgie F, Virmani R (2005) Thrombotic thrombocytopenic purpura causing rapid unexpected death. Cardiovasc Pathol 14:150-155. https://doi.org/10.1016/j.carpath. 2005.03.001

43. Nicholls JM, Poon LL, Lee KC et al (2003) Lung pathology of fatal severe acute respiratory syndrome. Lancet 361:1773-1778. https:// doi.org/10.1016/S0140-6736(03)13413-7

44. Franks TJ, Chong PY, Chui P, Galvin JR, Lourens RM, Reid AH, Selbs E, Mcevoy CPL, Hayden CDL, Fukuoka J, Taubenberger JK, Travis WD (2003) Lung pathology of severe acute respiratory syndrome (SARS): a study of 8 autopsy cases from Singapore. Hum Pathol 34:743-748. https://doi.org/10.1016/S0046-8177(03) 00367-8

45. Hwang DM, Chamberlain DW, Poutanen SM, Low DE, Asa SL, Butany J (2005) Pulmonary pathology of severe acute respiratory syndrome in Toronto. Mod Pathol 18:1-10. https://doi.org/10. 1038/modpathol.3800247

46. Gu J, Korteweg C (2007) Pathology and pathogenesis of severe acute respiratory syndrome. Am J Pathol 170:1136-1147. https:// doi.org/10.2353/ajpath.2007.061088
47. Alsaad KO, Hajeer AH, Al Balwi M et al (2018) Histopathology of Middle East respiratory syndrome coronavirus (MERS-CoV) infection-clinicopathological and ultrastructural study. Histopathology 72:516-524. https://doi.org/10.1111/his.13379

48. Ng DL, Al Hosani F, Keating MK et al (2016) Clinicopathologic, immunohistochemical, and ultrastructural findings of a fatal case of Middle East Respiratory Syndrome coronavirus infection in the United Arab Emirates, April 2014. Am J Pathol 186:652-658. https://doi.org/10.1016/j.ajpath.2015.10.024

49. Nakayama S, Yokote T, Hiraoka N (2017) Transforming growth factor $\beta$ - and interleukin 13-producing mast cells are associated with fibrosis in bone marrow. Hum Pathol 62:180-186. https:// doi.org/10.1016/j.humpath.2017.01.007

50. Zhou Y, Zhang B, Li C, Huang XT, Cheng HP, Bao XW, Zhao FY, Cheng QM, Yue SJ, Han JZ, Luo ZQ (2019) Megakaryocytes participate in the occurrence of bleomycin-induced pulmonary fibrosis. Cell Death Dis 10:648. https://doi.org/10.1038/s41419-019-1903-8

Publisher's note Springer Nature remains neutral with regard to jurisdictional claims in published maps and institutional affiliations. 